\title{
Early Changes in Rates of Documented Goals-of-Care Conversations in the Veterans Health Administration During the COVID-19 Pandemic
}

J Gen Intern Med 36(5):1466-9

DOI: $10.1007 / \mathrm{s} 11606-021-06652-5$

(C) This is a U.S. government work and not under copyright protection in the U.S.; foreign copyright protection may apply 2021

\section{INTRODUCTION}

Goals-of-care conversations (GoCCs) to elicit patients' values regarding end-of-life care, including lifesustaining treatment, are a hallmark of high-quality, patient-centered care. ${ }^{1}$ Ideally, GoCCs are proactive, held in outpatient settings before clinical deterioration; unfortunately, patients' first GoCCs are often delayed until hospitalization ("just-in-time"). ${ }^{1}$ The COVID-19 pandemic heightened the importance of proactive GoCCs, which can improve both patient-centered and population-level outcomes when life-sustaining treatment resources may be limited. ${ }^{1-3}$ It is unknown whether hospitals effectively and rapidly mobilized resources in response to calls to increase proactive GoCCs, ${ }^{2,}{ }^{3}$ or if they struggled to do so amidst competing demands during early COVID surges.

Over the past decade, the Veterans Health Administration (VA), the largest nationally integrated US healthcare system, implemented a multi-pronged approach to promote GoCCs, including a national policy, trainings, standardized templates to document GoCCs, and a dashboard for benchmarking GoCCs across facilities. ${ }^{4}$ Within the first year of dedicated implementation (by February 2019), approximately $25 \%$ of high-risk Veterans had documented GoCCs, ${ }^{5}$ suggesting VA's investment was generating early success, but with continued opportunity for improvement. To determine the degree to which individual hospitals in an integrated system responded to the heightened need for GoCCs during the early pandemic, we characterized changes in documented GoCC rates at $20 \mathrm{VA}$ facilities with high COVID caseloads.

Received August 16, 2020

Accepted February 3, 2021

Published online March 9, 2021

\section{METHODS}

We identified the 20 VA facilities with the most COVID cases through June 5, 2020 (range 257-898, all with first case by March 19, 2020). ${ }^{6}$ We used VA Support Service Center data to determine weekly counts of documented initial GoCCs (first standardized GoCC template in patient's record) for each facility over 1 year. We designated weeks 1-39 (June 1, 2019-February 28, 2020) "preCOVID" and weeks 40-52 (February 29-May 29, 2020) "COVID." One facility contributed only outpatient data (site L). We calculated mean weekly pre-COVID and COVID documented GoCC rates for each facility, stratified by inpatient versus outpatient setting, with denominators of inpatient or outpatient visits respectively (i.e., opportunities for GoCCs). We calculated rate ratios (COVID versus pre-COVID) and used single-variable linear regression models to assess associations between facility-level characteristics and rate ratios. We created visualizations of weekly GoCC counts for each facility (Fig. 1 shows exemplars). VA Boston Research and Development deemed this project exempt from institutional board review.

\section{RESULTS}

Overall, we identified 17,853 documented GoCCs (7589 outpatient, 10,264 inpatient). Table 1 shows facility-level characteristics and mean weekly documented GoCC rates. Most facilities had low mean weekly rates of proactive documented GoCCs pre-pandemic (mean 0.57 per 1000 outpatient visits), with rates varying more than 60 -fold across facilities. During the pandemic, fifteen facilities $(75 \%)$ increased mean weekly documented GoCC rates in at least one setting: 4/20 (20\%) in both, 2/20 (10\%) outpatient only, 9/20 (45\%) inpatient only. Notably, most facilities $(17 / 20,85 \%)$ maintained or increased outpatient documented GoCC rates during COVID (asterisks in Table 1). No facility-level characteristics were significantly associated with change from pre-COVID to COVID documented GoCC rates. 


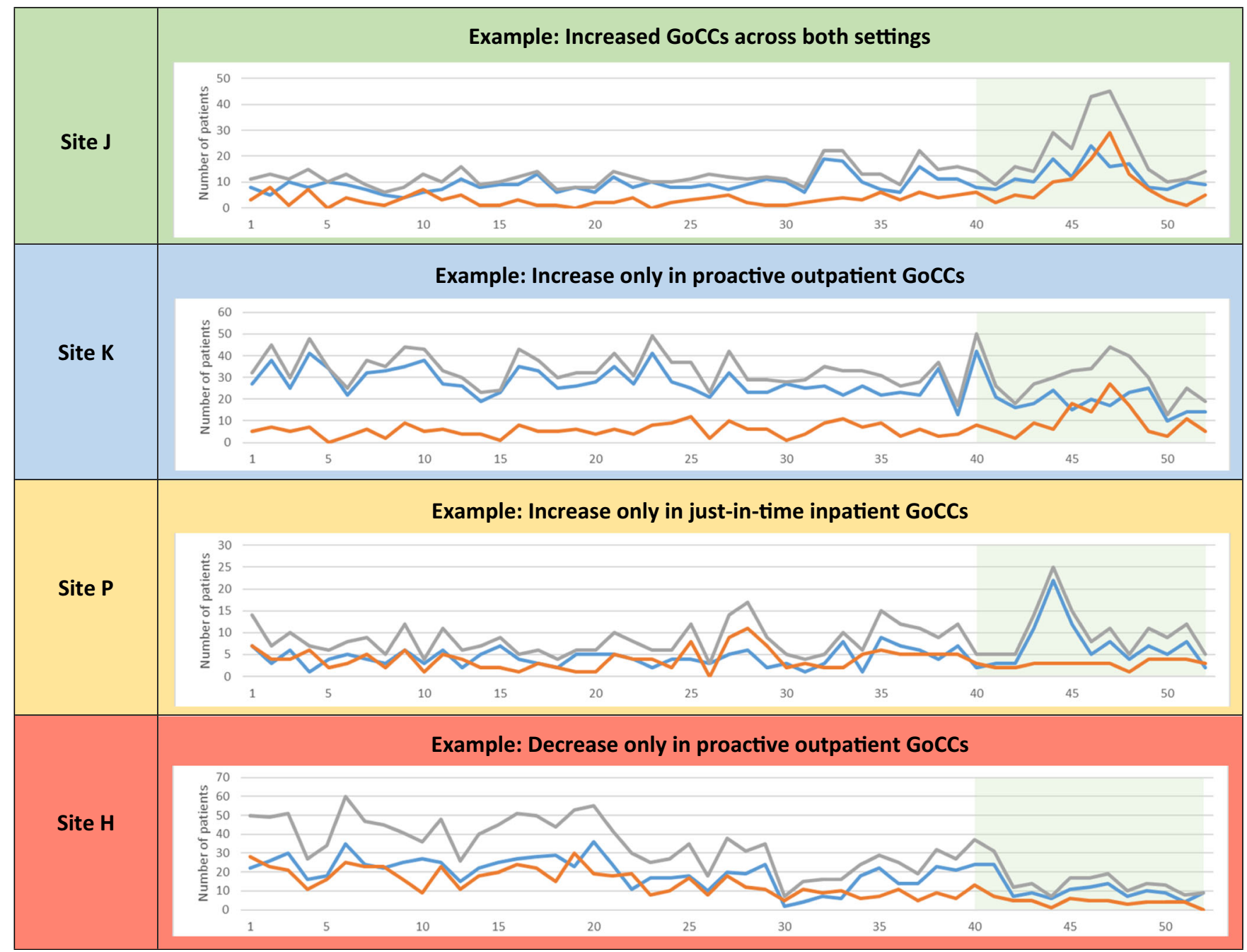

Figure 1 Exemplars of patterns of change observed in weekly documented GoCC counts in pre-COVID to COVID periods. GoCC, goals-ofcare conversation. Orange lines are outpatient; blue lines are inpatient; and gray lines are total. $X$-axis is time, in weeks; shading starting at week 40 indicates during the COVID pandemic. Scale of $\boldsymbol{Y}$-axis differs per facility.

\section{DISCUSSION}

During the early pandemic, the VA released a national memo and supporting trainings urging providers to conduct and document GoCCs, echoing calls from experts to prioritize proactive GoCCs during COVID. ${ }^{2,3}$ Yet it appears the pandemic's onset was insufficient to catalyze increased outpatient GoCC rates consistently across facilities (e.g., $30 \%$ of facilities in our study increased mean weekly proactive outpatient documented GoCC rates during COVID). The observed variability in changes in documented GoCC rates early in the pandemic is understandable: facilities may have been overwhelmed, with little time for providers to engage patients in GoCCs; transitioning to telehealth may have created additional barriers. Importantly, lessons could be learned from facilities that successfully increased proactive documented GoCC rates, in some instances 3-8-fold over baseline, early in the pandemic.

Our analysis has limitations. Our findings reflect changes during the early pandemic; documented GoCC rates likely evolved as facilities adapted to providing care during COVID. We only captured GoCCs documented in standardized templates; actual GoCC rates may be higher (e.g., if undocumented or documented in non-standard ways). Our findings may not generalize to non-VA settings. Future work should assess not only GoCC rates but also their quality and leverage opportunities to identify effective implementation strategies deployed in facilities that rapidly increased and sustained proactive, patient-centered GoCCs in this time of heightened need: the global COVID-19 pandemic. 
Table 1 Characteristics and Mean Weekly Documented GoCC Rates Before and During COVID of the 20 VA Facilities with the most COVID Cases During the Early Pandemic

\begin{tabular}{|c|c|c|c|c|c|c|c|c|c|c|c|}
\hline Site* & Region & Rurality & $\begin{array}{c}\text { Facility } \\
\text { size } \\
\text { (quartile) }\end{array}$ & $\begin{array}{c}\text { Palliative } \\
\text { care } \\
\text { (quartile) }\end{array}$ & $\begin{array}{c}\text { COVID } \\
\text { cases } \\
\text { (quartile) }\end{array}$ & $\begin{array}{c}\text { Pre-COVID } \\
\text { Mean (SD) per } \\
1000\end{array}$ & $\begin{array}{c}\text { During COVID } \\
\text { Mean (SD) per } \\
1000\end{array}$ & $\begin{array}{c}\text { Rate Ratio } \\
(95 \% \mathrm{Cl})\end{array}$ & $\begin{array}{c}\text { Pre-COVID } \\
\text { Mean (SD) per } \\
1000\end{array}$ & \begin{tabular}{|c|} 
During COVID \\
Mean (SD) per \\
1000 \\
\end{tabular} & $\begin{array}{c}\text { Rate Ratio } \\
(95 \% \mathrm{Cl})\end{array}$ \\
\hline & & & & & & \multicolumn{6}{|c|}{ Increased documented GoCC rates across both settings during COVID (4 facilities) } \\
\hline$I^{*}$ & Northeast & Urban & 1 & 1 & 1 & $0.37(0.58)$ & $3.10(3.25)$ & $8.53(6.67,10.9)$ & $26.02(37.33)$ & $113.04(138.19)$ & $3.72(1.95,7.11)$ \\
\hline D* & West & Urban & 4 & 3 & 2 & $0.05(0.11)$ & $0.25(0.16)$ & $4.93(3.23,7.52)$ & $28.18(57.92)$ & $123.84(51.83)$ & $4.36(3.41,5.56)$ \\
\hline J* & Northeast & Urban & 3 & 4 & 4 & $0.21(0.15)$ & $0.80(0.71)$ & $3.74(2.89,4.86)$ & $47.65(20.23)$ & $119.84(62.92)$ & $2.32(1.94,2.78)$ \\
\hline $\mathrm{R}^{*}$ & Northeast & Urban & 2 & 2 & 1 & $0.72(0.30)$ & $0.96(0.50)$ & $1.31(1.04,1.64)$ & $58.49(23.57)$ & $94.76(43.51)$ & $1.53(1.19,1.97)$ \\
\hline & & & & & & \multicolumn{6}{|c|}{ Increase only in proactive outpatient documented GoCC rates during COVID (2 facilities) } \\
\hline $\mathrm{K}^{*}$ & Northeast & Urban & 3 & 3 & 3 & $0.37(0.20)$ & $0.85(0.56)$ & $2.23(1.79,2.77)$ & $357.10(76.75)$ & $380.29(102.18)$ & $1.07(0.96,1.19)$ \\
\hline $\mathrm{L}^{*}$ & Northeast & Urban & 1 & 1 & 1 & $0.46(0.43)$ & $0.70(0.66)$ & $1.56(1.03,2.36)$ & $\mathrm{n} / \mathrm{a}$ & $\mathrm{n} / \mathrm{a}$ & $\mathrm{n} / \mathrm{a}$ \\
\hline & & & & & & \multicolumn{6}{|c|}{ Increase only in just-in-time inpatient documented GoCC rates during COVID (9 facilities) } \\
\hline B* & Midwest & Urban & 4 & 1 & 2 & $0.15(0.10)$ & $0.19(0.11)$ & $1.27(0.94,1.70)$ & $86.20(32.90)$ & $119.26(54.71)$ & $1.37(1.16,1.61)$ \\
\hline M* & Northeast & Urban & 1 & 2 & 4 & $0.17(0.15)$ & $0.20(0.20)$ & $1.21(0.68,2.15)$ & $46.71(20.28)$ & $134.07(103.78)$ & $2.69(2.02,3.57)$ \\
\hline S* & Northeast & Urban & 3 & 3 & 4 & $0.30(0.18)$ & $0.35(0.20)$ & $1.19(0.86,1.63)$ & $66.90(38.00)$ & $142.17(110.50)$ & $2.02(1.59,2.57)$ \\
\hline $\mathrm{N}^{*}$ & Midwest & Urban & 2 & 2 & 1 & $0.24(0.18)$ & $0.27(0.21)$ & $1.16(0.75,1.79)$ & $33.87(18.84)$ & $58.95(38.26)$ & $1.70(1.23,2.34)$ \\
\hline O* & Northeast & Urban & 2 & 4 & 4 & $0.39(0.19)$ & $0.45(0.35)$ & $1.10(0.82,1.48)$ & $68.33(28.08)$ & $152.50(60.20)$ & $2.20(1.85,2.61)$ \\
\hline P* & Southeast & Urban & 2 & 4 & 4 & $0.30(0.20)$ & $0.33(0.14)$ & $1.06(0.75,1.51)$ & 65.34 (31.90) & $141.13(118.16)$ & $2.00(1.57,2.54)$ \\
\hline $\mathrm{E}^{*}$ & Northeast & Urban & 1 & 1 & 2 & $0.39(0.28)$ & $0.39(0.26)$ & $0.97(0.65,1.46)$ & $67.59(42.16)$ & $125.54(162.06)$ & $1.77(1.31,2.40)$ \\
\hline $\mathrm{T}^{*}$ & Southeast & Urban & 4 & 3 & 2 & $0.33(0.42)$ & $0.28(0.14)$ & $0.84(0.67,1.06)$ & $45.90(21.88)$ & $68.05(28.07)$ & $1.50(1.19,1.88)$ \\
\hline $\mathbf{Q}$ & Southeast & Urban & 4 & 2 & 3 & $0.81(0.42)$ & $0.55(0.35)$ & $0.68(0.55,0.85)$ & 60.09 (34.39) & $165.46(55.19)$ & $2.64(2.22,3.15)$ \\
\hline & & & & & & \multicolumn{6}{|c|}{ Decrease only in proactive outpatient documented GoCC rates during COVID (2 facilities) } \\
\hline G & Midwest & Urban & 3 & 4 & 1 & $3.33(1.85)$ & $1.52(0.92)$ & $0.47(0.41,0.54)$ & $130.90(32.94)$ & $129.39(22.51)$ & $1.00(0.85,1.17)$ \\
\hline H & Northeast & Urban & 3 & 2 & 3 & $1.20(0.50)$ & $0.45(0.25)$ & $0.38(0.30,0.50)$ & $186.50(69.66)$ & $168.65(77.14)$ & $0.92(0.78,1.08)$ \\
\hline & & & & & & \multicolumn{6}{|c|}{ No significant change in documented GoCC rates in either setting during COVID (3 facilities) } \\
\hline $\mathrm{A}^{*}$ & Midwest & Urban & 1 & 1 & 3 & $0.11(0.14)$ & $0.16(0.16)$ & $1.48(0.75,2.92)$ & $162.45(45.50)$ & $147.26(51.48)$ & $0.90(0.74,1.09)$ \\
\hline $\mathrm{C}^{*}$ & Midwest & Urban & 4 & 4 & 2 & $1.40(1.06)$ & $1.45(0.96)$ & $1.08(0.94,1.24)$ & $79.09(28.71)$ & $94.25(41.68)$ & $1.20(0.99,1.45)$ \\
\hline $\mathrm{F}^{*}$ & Midwest & Urban & 2 & 3 & 3 & $0.20(0.18)$ & $0.12(0.11)$ & $0.60(0.34,1.06)$ & $264.53(46.60)$ & $249.61(53.43)$ & $0.94(0.85,1.05)$ \\
\hline
\end{tabular}

CI confidence interval, GoCC goals-of-care conversation, SD standard deviation, VA Veterans Health Administration. Sites organized by descending rate ratio in outpatient setting within each category. Region refers to US Census region; Facility size refers to number of Veterans who use the facility as their primary VA site of care; Palliative care refers to percent of Veterans served by the facility with palliative care utilization during the study period; COVID cases refers to unique individuals with SARS-CoV-2 infection during the study period. In all cases, first refers to lowest (0-25\%) and fourth refers to highest $(76-100 \%)$ quartile. Bolded rate ratios represent statistically significant $(p \leq 0.05)$ changes in mean weekly documented GoCC rates from pre-COVID to COVID

*Facilities that maintained or increased outpatient GoCC rates during COVID versus pre-COVID (i.e., either no statistically significant difference or a significant increase in rate ratio)

Renda Soylemez Wiener, MD, MPH ${ }^{1,2,3}$

So Yeon Kim, $\mathrm{MPH}^{1}$

Terri R. Fried, $M D^{4,5}$

Jennifer Cohen, $\mathrm{PhD}, \mathrm{MPH}^{6}$

Mary Beth Foglia, RN, PhD, $M A^{6}$

Lisa Soleymani Lehmann, $\mathrm{MD}, \mathrm{PhD}, \mathrm{MSc}^{7,8}$

Amy M. Linsky, MD, MSc ${ }^{1,2,9}$

${ }^{1}$ Center for Healthcare Organization and Implementation Research (CHOIR), VA Boston Healthcare System,

Boston, MA, USA

${ }^{2}$ Medicine Service, VA Boston Healthcare System,

Boston, MA, USA

${ }^{3}$ The Pulmonary Center, Boston University School of Medicine,

Boston, MA, USA

${ }^{4}$ Clinical Epidemiology Research Center, VA Connecticut Health Care System,

West Haven, CT, USA

${ }^{5}$ Department of Medicine, Yale School of Medicine,

New Haven, CT, USA
${ }^{6}$ National Center for Ethics in Health Care, Veterans Health Administration,

Washington, DC, USA

${ }^{7}$ VA New England Healthcare System,

Bedford, MA, USA

${ }^{8}$ Harvard Medical School,

Boston, MA, USA

${ }^{9}$ Section of General Internal Medicine, Boston University School of Medicine,

Boston, MA, USA

Corresponding Author: Renda Soylemez Wiener, MD, MPH; Center for Healthcare Organization and Implementation Research (CHOIR), VA Boston Healthcare System, Boston, MA, USA (e-mail: renda.wiener@va.gou).

Author Contribution Study concept and design: Wiener, Linsky. Acquisition of data: Kim, Linsky. Analysis and interpretation of data: Wiener, Kim, Fried, Cohen, Foglia, Lehmann, Linsky. Drafting of the manuscript: Wiener, Linsky. Critical revision of the manuscript for important intellectual content: Wiener, Kim, Fried, Cohen, Foglia, Lehmann, Linsky. Obtained funding: n/a. Study supervision: Linsky. 
Funding This study was supported in part by resources from the VA Boston Healthcare System and the VA Connecticut Healthcare System. The funding organizations had no role in the design and conduct of the study; the collection, management, analysis, and interpretation of the data; or the preparation, review, or approval of the manuscript.

\section{Declarations:}

Disclaimer: The views expressed herein do not necessarily represent the views of the Department of Veterans Affairs or the US Government.

Guarantor Statement: Dr. Linsky had full access to all of the data in the study and takes responsibility for the integrity of the data and the accuracy of the data analysis.

Conflict of Interest: The authors declare that they do not have a conflict of interest.

\section{REFERENCES}

1. Bernacki RE, Block SD. Communication about serious illness care goals: a review and synthesis of best practices. JAMA Intern Med. 2014;174(12): 1994-2003.
2. Block BL, Smith AK, Sudore RL. During COVID-19, Outpatient Advance Care Planning Is Imperative: We Need All Hands on Deck. J Am Geriatr Soc. 2020 Jul;68(7): 1395-1397.

3. Curtis JR, Kross EK, Stapleton RD. The Importance of Addressing Advance Care Planning and Decisions About Do-Not-Resuscitate Orders During Novel Coronavirus 2019 (COVID-19). JAMA. 2020;https://doi.org/ $10.1001 /$ jama.2020.4894.

4. Foglia MB, Lowery J, Sharpe VA, Tompkins P, Fox E. A Comprehensive Approach to Eliciting, Documenting, and Honoring Patient Wishes for Care Near the End of Life: The Veterans Health Administration's Life-Sustaining Treatment Decisions Initiative. Jt Comm J Qual Patient Saf. 2019;45(1):4756.

5. Levy C, Ersek M, Scott W, et al. Life-Sustaining Treatment Decisions Initiative: Early Implementation Results of a National Veterans Affairs Program to Honor Veterans' Care Preferences. J Gen Intern Med. 2020;35(6):1803-1812.

6. U.S. Department of Veterans Affairs. Department of Veterans Affairs COVID-19 National Summary. Available at: https://www.accesstocare.va. gov/Healthcare/COVID19NationalSummary. Accessed June 5, 2020.

Publisher's Note: Springer Nature remains neutral with regard to jurisdictional claims in published maps and institutional affiliations. 